\title{
HUBUNGAN ANTARA KELEKATAN ORANG TUA DENGAN KEDISIPLINAN SISWA DI MTS NURUL HUDA SEDATI
}

\author{
Septian Dwi Mursini ${ }^{1}$, Widyastuti ${ }^{2}$ \\ ${ }^{1,2}$ Fakultas Psikologi, Universitas Muhammadiyah Sidoarjo, Sidoarjo, Jawa Timur, Indonesia
}

\begin{abstract}
This research is a correlational quantitative method that is motivated by phenomena that seek to undiscipline in school environment. This study aims to determine whether there is a relationship between parents with discipline students in MTs Nurul Huda Sedati. Variables in this research is Parent attachment as independent variable $(X)$ and Discipline as independent variable $(Y)$. This research was conducted in MTs Nurul Huda Sedati covering class VII-IX with total sample of 221 students, taken using proporsionate stratified random sampling technique. Data collection in this research using psychological model that is Likert, that is IPPA scale (parent attachment) and disciplinary scale. Hypothesis in this research is there is positive relation between parent attachment with student discipline. Data analysis was done by statistical technique from Product Moment from Pearson using SPSS 18.0 for windows. The result of data analysis show open coefficient (rxy) = 0,285 with significance level 0.000 (less than 0,01) accepted hypothesis. The results showed there was a positive relationship between parents with discipline students in MTs Nurul Huda Sedati.
\end{abstract}

Keywords: Parental attachment, Discipline, students of MTs

\begin{abstract}
ABSTRAK
Penelitian ini merupakan penelitian metode kuantitatif pendekatan korelasional yang dilatarbelakangi oleh fenomena banyaknya siswa yang melakukan ketidakdisiplinan di dalam lingkungan sekolah. Penelitian ini bertujuan untuk mengetahui apakah terdapat hubungan antara kelekatan orang tua dengan kedisiplinan siswa di MTs Nurul Huda Sedati. Variabel dalam penelitian ini adalah Kelekatan orang tua sebagai variabel bebas (X) dan Kedisiplinan sebagai variabel terikat (Y). Penelitian ini dilakukan di MTs Nurul Huda Sedati yang meliputi kelas VII-IX dengan jumlah sampel sebanyak 221 siswa, yang diambil menggunakan teknik proporsionate stratified random sampling. Pengumpulan data dalam penelitian ini menggunakan dua skala psikologi model Likert, yaitu skala IPPA (kelekatan orang tua) dan skala Kedisiplinan. Hipotesis dalam penelitian ini adalah terdapat hubungan positif antara kelekatan orang tua dengan kedisiplinan siswa. Analisis data dilakukan dengan teknik statistik korelasi Product Moment dari Pearson menggunakan SPSS 18.0 for windows. Hasil analisis data penelitian ini menunjukkan koefisien korelasi ( $\mathrm{rxy})=0,285$ dengan taraf signifikansi 0,000 (lebih kecil dari 0,01) artinya hipotesis diterima. Hasil penelitian menunjukkan bahwa ada hubungan positif antara kelekatan orang tua dengan kedisiplinan siswa di MTs Nurul Huda Sedati.
\end{abstract}

Kata kunci : Kelekatan orang tua, Kedisiplinan, siswa MTs 
Psikologia (Jurnal Psikologi), Vol 2 (2), July 2017 , 105-115

ISSN 2338-8595 (print), ISSN 2541-2299 (online) Journal Homepage: http://ojs.umsida.ac.id/index.php/psikologia

DOI Link: 10.21070/psikologia.v2i2.1542

\section{PENDAHULUAN}

Pendidikan merupakan hal yang sangat penting bagi kehidupan manusia. Pendidikan adalah suatu usaha manusia (tenaga pendidik) untuk dengan penuh tanggung jawab membimbing anak-anak didik menuju tingkat kedewasaan. Dibutuhkan alat / instrumen pendidikan untuk membina sikap dan mental siswa didik. Salah satu alat pendidikan tersebut adalah kedisiplinan. (Dikti, 2016).

Kedisiplinan merupakan suatu ketaatan yang sungguh - sungguh dan didukung oleh kesadaran untuk menunaikan tugas dan kewajiban serta sikap dan perilaku sesuai dengan aturan yang seharusnya dilakukan didalam suatu lingkungan tertentu (Suratman, 1999).

Kedisiplinan nampak pada perilaku keseharian siswa di sekolah. Perilaku disiplin tersebut seperti tertib, jujur, tepat waktu dan tepat janji dapat diwujudkan dalam kehidupan sehari - hari (Muhamad, 2003). Kedisiplinan memiliki peranan bagi pelajar. Kedisiplinan dapat meningkatkan keberhasilan yang tinggi untuk kehidupan pelajar kedepannya. Disiplin merupakan suatu hal yang harus ditanamkan pada diri anak yang nantinya kemudian akan menjadi kebiasaan. Pengaruh kedisiplinan akan menjadikan pelajar memiliki tujuan yang jelas, dapat menempatkan diri dalam situasi apapun, karena kedisplinan merupakan salah satu indikator keberhasilan dan kesuksesan individu.

Peran penting kedisiplinan ditunjukkan di dalam penelitian yang dilakukan oleh Inayah (2010). Siswa yang disiplin cenderung memiliki prestasi belajar yang tinggi. Ada pula penelitian yang dilakukan oleh Dian, dkk (2013) juga menjelaskan lingkungan yang tertib dan disiplin juga ikut andil dalam lahirnya siswa-siswa yang berprestasi dengan kepribadian unggul karena disana terdapat kompetisi positif diantara mereka. Sikap yang disiplin akan membuat siswa memiliki kecakapan menangani cara belajar yang baik, juga merupakan suatu proses menuju pembentukan watak yang baik.

Menurut Hurlock (1980), masa remaja merupakan masa peralihan dari masa anak anak ke masa dewasa, masa ini dimulai saat anak secara seksual matang dan berakhir saat mencapai usia matang secara hukum. Masa remaja disebut sebagai masa krisis, yang mana perubahan terjadi sangat drastis dan mengakibatkan terjadinya kondisi yang serba tanggung dan diwarnai oleh kondisi psikis yang belum mantap. Pada masa 
Psikologia (Jurnal Psikologi), Vol 2 (2), July 2017 , 105-115

ISSN 2338-8595 (print), ISSN 2541-2299 (online)

Journal Homepage: http://ojs.umsida.ac.id/index.php/psikologia

DOI Link: 10.21070/psikologia.v2i2.1542

remaja ini, individu mulai menginjak masa dewasa akhir dan artinya ia telah mencapai usia matang secara hukum. Masa ini individu dituntut untuk dapat lebih menerapkan kemandirian dalam mempelajari segala sesuatunya agar proses untuk menjadi individu yang dewasa lebih mudah terpenuhi dan dalam hal ini remaja membutuhkan dukungan dari orang terdekat, salah satunya yaitu orang tua. Banyak para remaja yang mengalami krisis kemandirian menunjukkan perilaku - perilaku yang negatif.

Realitas menunjukkan, masalah ketidakdisiplinan yang dilakukan oleh remaja banyak terjadi di Indonesia. Seperti pada Beritasidoarjo.com pada tanggal 5 November 2014 menjelaskan bahwa "Satpol PP Kabupaten Sidoarjo berhasil mengamankan 9 pelajar SMP dan SMA yang diketahui membolos pada saat jam-jam pelajaran”. Tanggal 30 Agustus 2016 juga mengabarkan "Polsek Trawas menggelar razia dan menangkap sedikitnya 6 pelajar asal Sidoarjo yang diketahui membolos" (beritajatim.com). Kedisiplinan saat ini menjadi hal yang sepele bagi masyarakat, khususnya yang terjadi di sekolah. Pemaparan pemberitaan di atas tergambar betapa memprihatinkannya perilaku yang sebagai bentuk dari kedisiplinan remaja mulai diindahkan.

Madrasah tsanawiyah (MTs) adalah salah satu jenjang dasar pada pendidikan formal di Indonesia, setara dengan sekolah menengah pertama, yang pengelolaannya dilakukan oleh Departemen Agama. MTs Nurul Huda Sedati merupakan Lembaga Pendidikan Islam dibawah Yayasan Pendidikan Islam Nurul Huda Sedati. MTs Nurul Huda Memiliki model pembelajaran berbasis IPTEK yang selalu didasari oleh IMTAQ dan akhlaqul karimah.

Ketidakdisiplinan juga terjadi di Mts Nurul Huda. Hasil wawancara dengan guru BK di MTs Nurul Huda Sedati pada tanggal 17 Oktober 2016, didapati hasil bahwa terdapat beberapa siswa di MTs Nurul Huda yang tidak disiplin, tidak disiplin ini mulai dari hal terlambat datang kesekolah, mengerjakan tugas tidak tepat waktu, membolos, tidak memakai atribut sekolah, ramai dikelas hingga terjadi kasus bullying, dan hal ini menjadi perhatian dari pihak sekolah.

Wawancara kedua tanggal 29 November dengan Guru BK Kelas 9, guru menuturkan memang terdapat ketidakdisiplinan seperti tidak membawa perlengkapan sholat dhuha, terlambat 
Psikologia (Jurnal Psikologi), Vol 2 (2), July 2017 , 105-115

ISSN 2338-8595 (print), ISSN 2541-2299 (online)

Journal Homepage: http://ojs.umsida.ac.id/index.php/psikologia

DOI Link: 10.21070/psikologia.v2i2.1542

datang, membolos, dan tidak mengerjakan PR.

Guru menambahkan bahwa ketidakdisiplinan ini merupakan hasil dari kedekatan anak dengan orang tua yang kurang. Siswa yang tidak disiplin dikarenakan orang tua yang bekerja dari pagi, ada pula siswa yang mengalami Orang tua bercerai sehingga banyak yang terlambat datang kesekolah. Guru juga menyatakan bahwa ketidakdisiplinan ini wujud ketidakpuasan anak terhadap orang tua, rasa berontak terhadap orang tua dan wujud penolakan anak terhadap orang tua sehingga anak melampiaskan rasa tersebut di sekolah.

Menurut data sekolah, ketidakdisiplinan yang dilakukan oleh siswa MTs Nurul Huda Sedati pada tahun 2016 sebanyak 6\% dari keseluruhan siswa. Hal ini kemungkinan dapat bertambah pula dengan seiring berjalannya waktu, karena masa remaja merupakan masa yang rentan terhadap rasa ingin tahu siswa terhadap hal-hal baru.

Data yang diperoleh dari wawancara dan data sekunder menunjukkan bahwa siswa MTs Nurul Huda Sedati tidak disiplin. Ditunjukkan dengan perilaku terlambat datang kesekolah, mengerjakan tugas tidak tepat waktu, membolos, tidak memakai atribut sekolah, tidak membawa perlengkapan sholat, ramai dikelas hingga terjadi kasus bullying.

Terdapat beberapa faktor yang mempengaruhi kedisiplinan siswa menurut penelitian terdahulu, salah satunya yaitu komunikasi remaja dan orang tua (Baiti, 2014). Pola komunikasi orang tua-anak yang baik dapat membuat siswa menunjukkan sikap disiplin yang baik pula, karena orang tua merupakan teladan untuk anak. Sikap yang disiplin tersebut ditunjukkan seperti sikap dengan perbuatan yang sesuai, datang ke sekolah, masuk kelas dan menerima pelajaran, dan pulang sekolah tepat waktu. Pada penelitian komunikasi remaja - orang tua (Ma'rifah, 2012) juga menjelaskan bahwa komunikasi remaja dan orang tua berkorelasi positif, yang artinya komunikasi yang baik antara remaja dan orang tua sangat besar manfaatnya bagi remaja, karena semakin baik jalinan komunikasi antara remaja dan orang tua maka semakin baik pula disiplin para remaja. Kedisiplinan yang diterapkan di sekolah akan memberikan andil bagi perkembangan karakter dan motivasi siswa untuk bersaing secara sehat dalam meraih prestasi.

Berdasarkan penjelasan di atas, kedekatan nampak pada kelekatan orang tua. Kedisiplinan sangat berkaitan dengan 
Psikologia (Jurnal Psikologi), Vol 2 (2), July 2017 , 105-115

ISSN 2338-8595 (print), ISSN 2541-2299 (online) Journal Homepage: http://ojs.umsida.ac.id/index.php/psikologia

DOI Link: 10.21070/psikologia.v2i2.1542

kelekatan orang tua dengan anak. Kelekatan memiliki peranan penting dalam membantu remaja untuk memenuhi tugas - tugas perkembangannya, khususnya untuk mencapai kedisiplinan siswa, seperti yang diutarakan oleh guru BK MTs Nurul Huda, terdapat dari siswa mereka yang tidak disiplin karena hubungan mereka dengan orang tua mereka yang kurang baik, sehingga dari wujud ketidakpuasan anak terhadap orang tua, rasa berontak terhadap orang tua dan wujud penolakan anak terhadap orang tua sehingga anak melampiaskan rasa tersebut di sekolah dan anak cenderung menjadi tidak disiplin.

Berdasarkan hal tersebut, maka dapat dipahami lingkungan keluarga merupakan salah satu lembaga yang mengemban tugas serta tanggung jawab dalam pencapaian tujuan pendidikan. Perilaku orang tua memegang peranan besar pada anak dimasa yang akan mendatang, karena pada masa remaja merupakan periode kritis yang nantinya menjadi dasar bagi berhasil atau tidaknya anak dalam menjalankan tugas perkembangan selanjutnya. Suharsimi Arikunto (1980) menyatakan bahwa sikap disiplin yang dibawa dari rumah sangat menentukan warna disiplin siswa di sekolah. Orang tua yang membiasakan anak untuk disiplin waktu dirumah akan membuat anak terbiasa menaati tata tertib di sekolah pula. Orang tua yang selalu memperhatikan kelengkapan dan keperluan anak di sekolah agar siswa tertib dalam menaati peraturan di sekolah. Anak yang dekat dengan orang tua juga akan senantiasa diberi bimbingan agar anak berperilaku baik di sekolah.

Berdasarkan penelitian terdahulu dan fenomena yang ada. Hal ini menggugah peneliti tentang pentingnya mengetahui dan memperdalam masalah kedisiplinan siswa. Dengan demikian peneliti ingin mengadakan penelitian mengenai Hubungan antara Kelekatan Orang Tua dengan kedisiplinan siswa di MTs Nurul Huda Sedati.

\section{METODE PENELITIAN}

Pendekatan dalam penelitian ini yaitu menggunakan metode penelitian kuantitatif yang menekankan analisisnya pada data-data numerical (angka) yang kemudian diolah dengan metode statistika (Azwar, 2007). Sedangkan penelitian ini menggunakan jenis penelitian korelasional (correlational research), yaitu penelitian yang menghubungkan dua variabel atau lebih. Penelitian korelasional bertujuan untuk menyelidiki sejauh mana variasi pada satu variabel berkaitan dengan variasi pada satu 
Psikologia (Jurnal Psikologi), Vol 2 (2), July 2017 , 105-115

ISSN 2338-8595 (print), ISSN 2541-2299 (online) Journal Homepage: http://ojs.umsida.ac.id/index.php/psikologia

DOI Link: 10.21070/psikologia.v2i2.1542

variabel ataupun lebih, berdasarkan koefisien korelasi (Azwar, 2012).

Populasi adalah keseluruhan subyek penelitian (Arikunto, 2002). Winarsunu (1996) menjelaskan bahwa populasi adalah seluruh individu yang dimaksudkan untuk diteliti dan kemudian nantinya akan digeneralisasikan

Populasi dalam penelitan ini adalah siswa MTs Nurul Huda Sedati. Jumlah keseluruhan siswa berdasarkan data 20162017 sebanyak 604 siswa.

Tabel 1. Jumlah populasi siswa Mts Nurul Huda Sedati

\begin{tabular}{ccc}
\hline No. & Kelas & Jumlah Siswa \\
\hline 1 & 1 & 219 \\
\hline 2 & 2 & 207 \\
\hline 3 & 3 & 178 \\
\hline
\end{tabular}

Pemilihan sampel pada penelitian ini menggunakan tabel Isaac dan Michael dengan taraf signifikansi 5\% dengan jumlah populasi 604 maka jumlah sampel yang diambil adalah 221 siswa.

Teknik Probability Sampling yang dipakai pada penelitian ini adalah menggunakan teknik proporsionate stratified random sampling. Pemilihan sampling dikarenakan populasi siswa MTs Nurul Huda Sedati merupakan suatu strata yang bertingkat dari kelas 1, 2 dan 3. Jadi secara keseluruhan terdapat 3 strata untuk pengambilan sampel dalam penelitian yang terdiri dari 221 siswa.

Table 2. Jumlah sampel Siswa MTs Nurul Huda Sedati

\begin{tabular}{cccc}
\hline Kelas & $\mathbf{1}$ & $\mathbf{2}$ & $\mathbf{3}$ \\
\hline Populasi & 219 & 207 & 178 \\
\hline Sampel & 80 & 76 & 65 \\
\hline
\end{tabular}

\section{HASIL PENELITIAN}

\section{Uji Asumsi}

Sebelum melakukan pengujian hipotesis maka terlebih dahulu peneliti harus melakukan uji asumsi yang merupakan syarat untuk dilakukannya pengetesan terhadap nilai korelasi antara kelekatan orang tua dengan kedisiplinan.

\section{Uji Normalitas}

Uji normalitas diberlakukan terhadap variabel bebas dan variabel terikat yaitu variabel kelekatan orang tua dan variabel kedisiplinan. Uji normalitas dilakukan dengan menggunakan SPSS 18.0 dengan uji Kolmogorov-Smirnov. 
DOI Link: 10.21070/psikologia.v2i2.1542

\section{Tabel 3. Hasil Uji Normalitas}

\begin{tabular}{|c|c|c|c|}
\hline \multicolumn{4}{|c|}{ One-Sample Kolmogorov-Smirnov Test } \\
\hline & & Kedisiplinan & Kelekatan \\
\hline $\mathrm{N}$ & & 221 & 221 \\
\hline \multirow[t]{2}{*}{ Normal Parameters ${ }^{a, b}$} & Mean & 83,8462 & 104,3258 \\
\hline & Std. Deviation & 7,74267 & 11,37632 \\
\hline Most Extreme & Absolute & 052 & ,076 \\
\hline \multirow[t]{2}{*}{ Differences } & Positive & 035 & 044 \\
\hline & Negative &,- 052 &,- 076 \\
\hline \multicolumn{2}{|l|}{ Kolmogorov-Smirnov Z } & ,770 & 1,128 \\
\hline \multicolumn{2}{|l|}{ Asymp. Sig. (2-tailed) } & ,594 & 157 \\
\hline \multicolumn{4}{|c|}{ a. Test distribution is Normal. } \\
\hline
\end{tabular}

Berdasarkan data tabel 4.1 di atas dapat diketahui bahwa Nilai signifikansi uji normalitas kelekatan orang tua adalah 0,157 yang berarti nilai tersebut lebih besar dari 0,05. Sedangkan nilai signifikansi uji normalitas pada variabel kedisiplinan adalah 0,594 yang berarti lebih besar dari 0,05 sehingga dapat disimpulkan bahwa distribusinya normal.

\section{Uji Linieritas}

Uji linieritas merupakan pengujian garis regresi antar variabel bebas dengan variabel terikat. Uji linieritas hubungan dilakukan terhadap variabel kelekatan orang tua dengan variabel kedisiplinan. Uji linieritas hubungan tersebut dilakukan dengan menggunakan bantuan program SPSS 18 for windows.
Pedoman untuk mengambil keputusan dari hasil uji linieritas (Widhiarso, 2010) adalah dengan melihat hasil signifikansi (sig) pada kolom Linearity

\section{.Table 4. Hasil Uji Linieritas}

\begin{tabular}{|c|c|c|c|c|c|c|c|}
\hline \multicolumn{8}{|c|}{ ANOVA Table } \\
\hline & & & Sum of & & Mean & & \\
\hline & & & Squares & Df & Square & $\mathrm{F}$ & Sig. \\
\hline kedisiplinan & Between & (Combined) & 4223,259 & 48 & 87,985 & 1,688 &, 008 \\
\hline \multirow[t]{5}{*}{ * kelekatan } & Groups & Linearity & 1069,035 & 1 & 1069,035 & 20,509 &, 000 \\
\hline & & $\begin{array}{l}\text { Deviation } \\
\text { from Linearity }\end{array}$ & 3154,224 & 47 & 67,111 & 1,288 & , 125 \\
\hline & Within $\mathrm{Gr}$ & ups & 8965,511 & 172 & 52,125 & & \\
\hline & Total & & 13188,76 & 220 & & & \\
\hline & & & 9 & & & & \\
\hline
\end{tabular}

Hasil uji linieritas yang ditunjukkan pada tabel 4.2 di atas diperoleh $\mathrm{F}$ sebesar 20,509 dengan signifikansi 0,000. Maka hal ini berarti nilai signifikansi lebih kecil dari 0,05 sehingga dapat diasumsikan bahwa data memiliki korelasi yang linier.

\section{Uji Analisa Data}

Hipotesis yang digunakan pada penelitian ini adalah terdapat hubungan positif antara kelekatan orang tua dengan kedisiplinan. Tekhnik statistik yang digunakan untuk menguji hipotesis pada penelitian ini adalah korelasi Product Moment dari Pearson dan dihitung 
menggunakan SPSS 18 for windows.

Adapun hasil dari uji korelasi antar variabel dapat dilihat pada tabel 5. berikut :

Table 5. Hasil Uji Korelasi

\begin{tabular}{|c|c|c|c|}
\hline \multicolumn{4}{|c|}{ Correlations } \\
\hline & & Kedisiplinan & kelekatan \\
\hline \multirow[t]{3}{*}{ Kedisiplinan } & Pearson Correlation & 1 & ,285 \\
\hline & Sig. (2-tailed) & &, 000 \\
\hline & $\mathrm{N}$ & 221 & 221 \\
\hline \multirow[t]{3}{*}{ Kelekatan } & Pearson Correlation &, $285^{* *}$ & 1 \\
\hline & Sig. (2-tailed) &, 000 & \\
\hline & $\mathrm{N}$ & 221 & 221 \\
\hline
\end{tabular}

Berdasarkan tabel 4.3 di atas dapat diketahui bahwa hasil koefisien korelasi $=$ $0.285^{* *}$ dengan signifikansi $0,000<0,01$. Dapat disimpulkan bahwa terdapat hubungan positif yang signifikan antara kelekatan orang tua dengan kedisiplinan, sehingga hipotesis yang diajukan pada penelitian ini dapat diterima. Hal ini berarti bahwa semakin tinggi kelekatan orang tua maka semakin tinggi pula kedisiplinan siswa, begitupun sebaliknya semakin rendah kelekatan orang tua maka rendah pula kedisiplinan siswa tersebut.

Penelitian ini juga menghitung efektivitas variabel kelekatan orang tua mempengaruhi kedisiplinan dengan Uji R2 atau koefisien Determinasi, dan hasilnya sebagai berikut :
Tabel 6. Uji Determinasi

\begin{tabular}{lrrrr}
\hline \multicolumn{5}{c}{ Model Summary } \\
\hline Model & \multicolumn{2}{c}{$\mathrm{R}$} & & \multicolumn{1}{c}{ Std. Error of } \\
& $\mathrm{R}$ & Square & Adjusted R Square & the Estimate \\
\hline 1 &, $285^{\mathrm{a}}$ &, 081 &, 077 & 7,43917 \\
\hline \multicolumn{2}{l}{ a. Predictors: (Constant), KELEKATAN } & &
\end{tabular}

Berdasarkan hasil uji koefisien determinasi pada tabel 6 menunjukkan 0,077 (Adjusted R Square) yang menunjukkan bahwa dalam penelitian ini variabel kelekatan orang tua memberikan sumbangan efektif sebesar $7,7 \%$ terhadap variabel kedisiplinan. Sisanya dapat dijelaskan oleh faktor-faktor penyebab lain yang tidak menjadi fokus dalam penelitian ini.

\section{PEMBAHASAN}

Berdasarkan dari hasil analisis data analisa di atas, hasil penelitian menunjukkan hasil koefisien korelasi $=0.285^{* *}$ dengan signifikansi $0,000<0,01$. Hal ini dapat disimpulkan bahwa terdapat hubungan positif yang signifikan antara kelekatan orang tua dengan kedisiplinan, sehingga hipotesis yang diajukan pada penelitian ini dapat diterima. Hal ini berarti bahwa semakin tinggi kelekatan orang tua maka semakin tinggi pula kedisiplinan siswa, begitupun sebaliknya semakin rendah 
Psikologia (Jurnal Psikologi), Vol 2 (2), July 2017 , 105-115

ISSN 2338-8595 (print), ISSN 2541-2299 (online) Journal Homepage: http://ojs.umsida.ac.id/index.php/psikologia

DOI Link: 10.21070/psikologia.v2i2.1542

kelekatan orang tua maka rendah pula kedisiplinan siswa tersebut.

Hasil penelitian ini sesuai penelitian sebelumnya yang dilakukan oleh Ma'rifah (2012) dengan judul Hubungan antara Komunikasi Remaja dan Orang Tua dan Disiplin di MAN Maguwoharjo. Hasil penelitian menunjukkan efektivitas variabel komunikasi anak dengan orang tua memberikan sumbangan sebesar $29,7 \%$. Komunikasi sangat berpengaruh terhadap kelekatan seorang anak dengan orang tuanya (Katorski, 2003). Komunikasi orang tua dengan anak yang baik merupakan hasil dari proses yang panjang selama masa perkembangan dari kecil hingga dewasa yang terdapat dalam kelekatan anak dengan orang tua. Komunikasi dijadikan dasar dalam terbentuknya kelekatan antara remaja dengan orang tua. Interaksi yang konsisten antara orang tua dan remaja terbukti dapat membangun kelekatan antara remaja dengan orang tua (Bowlby, 2008).

Sehingga dapat disimpulkan bahwa siswa MTs Nurul Huda Sedati memiliki tingkat kelekatan orang tua yang sedang. Hal ini sesuai dengan penelitian Raffaelli (2000) yang menjelaskan jika diusia remaja, interaksi dengan orang tua masih dibutuhkan meskipun sebagian besar waktu yang dihabiskan adalah dilingkungan baru di luar keluarga. Remaja pada rentang usia $12-15$ tahun sebagian besar juga mengatakan jika orang tua merupakan figur penting dan signifikan dalam hidup mereka.

Siswa yang memiliki kelekatan dengan orang tua dapat membuat siswa disiplin dalam sekolahnya. Karena dengan adanya kelekatan antara anak terhadap orang tua menjadikan perkembangan mental anak akan berkembang dengan baik. Orang tua yang dekat dengan anak akan mampu mencurahkan segenap rasa kasih sayangnya secara maksimal, ketika kebutuhan akan kasih sayang anak telah tercukupi, anak akan merasa dihargai secara penuh dan memiliki rasa percaya diri untuk menjalani aktivitasnya diluar lingkungan keluarga atau didalam kehidupan sosial yang lebih luas.

Meski telah tergambar kelekatan orang tua memiliki hubungan yang positif dengan kedisiplinan siswa. Namun berdasarkan hasil uji koefisien determinasi pada penelitian ini membuktikan bahwa variabel kelekatan orang tua hanya memberikan sumbangan efektif hanya sebesar $7,7 \%$ terhadap kedisiplinan siswa pada siswa di MTs Nurul Huda Sedati. Kondisi ini menunjukkan 
Psikologia (Jurnal Psikologi), Vol 2 (2), July 2017 , 105-115

ISSN 2338-8595 (print), ISSN 2541-2299 (online) Journal Homepage: http://ojs.umsida.ac.id/index.php/psikologia

DOI Link: 10.21070/psikologia.v2i2.1542

bahwa tingkat konsistensi variabel kelekatan orang tua hanya memberikan sedikit sumbangan terhadap variabel kedisiplinan dan sisanya ditentukan oleh faktor-faktor lain yang mempengaruhi kedisiplinan siswa.

Kegagalan anak dalam menjalin kelekatan dengan orang tua akan dapat menimbulkan masalah emosional dan moral. Menurut Jacinta (2002) Remaja yang kebutuhan emosionalnya tidak terpenuhi akibat dari adanya problem kelekatan yang dialami, nantinya akan berpotensi mengalami masalah intelektual, emosional, moral dan sosial dikemudian hari yang lebih besar. Pola perilaku beresiko tersebut seperti mengkonsumsi minuman keras, aktivitas seksual, hingga penyalahgunaan obat terlarang (Papalia, 2008).

Remaja yang memiliki kelekatan dengan orang tuanya ia akan merasa aman dan nyaman ketika berada dalam lingkungan keluarganya. Hal ini membuat remaja merasa tidak terabaikan dan tidak mudah marah ketika dalam lingkungan yang baru, sehingga ia lebih mudah menempatkan dirinya dan lebih dapat memahami peraturan ataupun norma yang ada. Ikatan yang sehat antara orang tua dengan remaja akan dapat membantunya dalam melakukan proses penyesuaian diri terutama dalam menyesuaikan dengan norma atau peraturan yang ada dilingkungannya, baik didalam lingkungan keluarga itu sendiri ataupun di lingkungan sekolah sehingga anak anak cenderung disiplin dalam berbagai hal.

Dengan diterimanya hipotesis dalam penelitian ini, maka menunjukkan bahwa terdapat hubungan yang signifikan antara kelekatan orang tua dengan kedisiplinan siswa. Adanya kelekatan orang tua dapat berakibat pada perilaku disiplin siswa. Berdasarkan pembahasan ini, maka dapat disimpulkan bahwa kelekatan terhadap orang tua dapat mempengaruhi kedisiplinan siswa dilingkungan sekolah.

\section{SIMPULAN}

Berdasarkan hasil penelitian dan pembahasan yang telah dilakukan, maka dapat disimpulkan bahwa terdapat hubungan positif antara kelekatan orang tua dengan kedisiplinan siswa di MTs Nurul Huda Sedati, penelitian ini dengan diperoleh hasil koefisien korelasi $(\mathrm{rxy})=0.285^{* *}$ dengan signifikansi $\mathrm{p}=0,000<0,05$. Hal ini berarti bahwa ada hubungan positif yang signifikan antara kelekatan orang tua dengan kedisiplinan siswa. Hal ini berarti semakin tinggi kelekatan orang tua maka semakin 
tinggi kedisiplinan siswa di MTs Nurul Huda Sedati, begitupun sebaliknya semakin rendah kelekatan orang tua maka semakin rendah kedisiplinan siswa di MTs Nurul Huda Sedati. Sumbangan efektif Kelekatan orang tua terhadap kedisiplinan siswa di MTs Nurul Huda Sedati sebesar 7,7\%. Sedangkan sisanya dipengaruhi oleh faktor lain.

\section{DAFTAR PUSTAKA}

Adisti. (2014). Studi Deskriptif Intensitas Perhatian Orang tua Dalam Kedisiplinan Siswa SD Negeri 01 Kota Bengkulu. Skripsi. Bengkulu: Fakultas Keguruan dan Ilmu Pendidikan Universitas Bengkulu.

Arikunto, S. (1980). Manajemen Pengajaran Secara Manusiawi . Jakarta: Rineka Cipta.

Azwar, S. (2012). Metode Penelitian. Yogyakarta: Pustaka Belajar.

Azwar, S. (2015). Penyusunan Skala Psikologi (edisi 2). Yogyakarta: Pustaka Belajar.

Baiti, E. (2014). Pengaruh Pola Komunikasi Orang tua-Anak Terhadap Kedisiplinan Belajar Siswa. Vol 2 No 1.

Bowlby, R. (2008). Attachment, what it is, why it is importantand we can do about it to help young children acquire a secure attachment. attachment theory: how to Help Young Children Acquire a Secure Attachment .
Greenberg, M. T., \& Armsden, G. (2009). IPPA. Inventory Of Parent and Peer Attachment. diunduh di https://dtreboux.files.wordpress.com pada tanggal 02 Januari 2017

Idaini, M. W. (2014). Hubungan Antara Kecerdasan Spiritual Keagamaan Dengan Sikap Disiplin Siwa Di Lingkungan Sekolah. Skripsi.Yogyakarta: Fakultas Ilmu Tabiyah dan Keguruan Universitas Islam Negeri Sunan Kalijaga.

Katorski， J. (2003). Father/Daughter relationship: Effects Of Communicative Adaptability And Satisfaction On Daughter's Romantic Relationship. Journal of Undergraduate Research, 52-56.

Suharsimi, A. (1980). Manajemen Pengajaran Secara Manusiawi. Jakarta: Rineka Cipta. 